\title{
Simulation Model to Management for Trains Movement
}

\author{
Zinah Salih Hussein \\ Computer science, Al Mustansiriyah University \\ Baghdad_Iraq
}

\author{
Basim Khudair Abbas \\ Mathematic science Al Mustansiriyah \\ University, Baghdad_Iraq
}

\begin{abstract}
A train movement approach proposed in this paper which is based on calculated "times of train spent on railway until access to next station" by applying several strategies to solve problem for a railway such as (priority, parallel) strategy. Also the aim is to reduce waiting time for trains during transition from station to next stations.

In this paper depended a best algorithm called discrete probability distributed to simulate operations for train through moving on railway, such as access time, waiting time, leave time, etc. also concluded double directions is best than single direction because its prevent conflict with other trains and not required waiting time.
\end{abstract}

\section{Keywords}

Train, railway, simulation, station, single-direction, doubledirection.

\section{INTRODUCTON}

The rail network consist of single-track lines while other locations consist of double- or triple-track lines. Because of varying local conditions, different points in the rail network may have different speed limits. Especially in densely populated metropolitan areas typically encounter complex trackage configurations. To make optimal use of the available rail capacity, some portions for graphical technique modeling such complex rail networks; and use this technique to develop a deadlock-free algorithm for dispatching each train to its destination with nearly minimal travel time while abiding by the speed limits at each point on each train's route, and maintaining adequate headways between trains.[1]

The development of a network model, including lines and stations, capable to simulate the traffic operations on the basis of the actions performed by the signaling components; this approach allows a high flexibility and capability to manage the traffic command and control operation. therefore need several models applied on the railway to increasing attention towards interoperability and safety arise and capable to support the decision processes concerning the system upgrade, particularly for the performances of the signaling in terms of carrying capacity and safety. [2]

The goals for this paper are a simulation models designed to reduce waiting time for trains access to stations and prevent to conflict with other trains on same direction in the railway.

\section{RELATED WORKS}

Shigeyuki Okazaki at 2000 discussed the concept for the development of computer simulation model for pedestrian movement in architectural and urban space. The characteristic of the model was the ability to visualize the movement of each pedestrian in a plan as an animation. So architects and designers could easily found and understand the problems in their design projects. In this model, the movement of each pedestrian was simulated by the motion of a magnetized object in a magnetic field.[3]

Y. Bavafa-Toosi at 2008 described the theoretic system about train traffic in a large railway network, by constrained statespace model. and is presented the novelty of work the transformation or rather reduction of the directed graph of the network to some parallel lists. Mathematization of this sophisticated problem was thus circumvented. on the other hand the aspects of a real network were completely captured by this model. [4]

J. Manuel Feliz-Teixeira at 2007 presented the circles model view purposed to understand that a metro-line, like a bridge or a molecule, had a certain proper frequency for being operated, which may be seen as the frequency to which its imbalance was minimal. on the other hand that represented too much pressure on the metro-line; less than that would mean too little pressure on it.[5]

Ye Jing-Jing at 2012 discussed the optimal velocity carfollowing model, and proposed simulation model for optimizing train movement in railway traffic. Here a kind of single-track railway was considered. Also the aim was to reduce the energy consumption of train movement and ensure the train being on time by controlling the velocity curve of train movement. The simulation results indicate that the proposed model was effective for optimizing train movement.[6]

\section{SYSTEM DESCRIPTION}

Trains often operate around the clock, meaning that two groups working alternately in order to keep a provide service for a passengers for daily and night to access on specific time without delay, therefore two 12-hour trains starting of work at 06:00 and 18:00. trains toward to station and stay to ride passengers then toward to other stations until arrival all passengers for demand places.

\subsection{Acknowledging with the Proposing System}

The proposed system is simulate train movement model. A train arrival to first station and stay until ride all passenger then toward to second station and waiting until descent of passengers. Some railway consisting of single-direction, double-direction or may be more direction. In state of singledirection a train wait until traffic other trains because the trains move in opposite direction on same railway and causes to conflict; otherwise the railway for double-directions, train continues to next station even other train arrival on the opposite direction without any conflict and not wait time to traffic other trains. Train continues to moving until stop on the last station. as Figure (1) summarize the trains flow through the railway by a flow chart. 


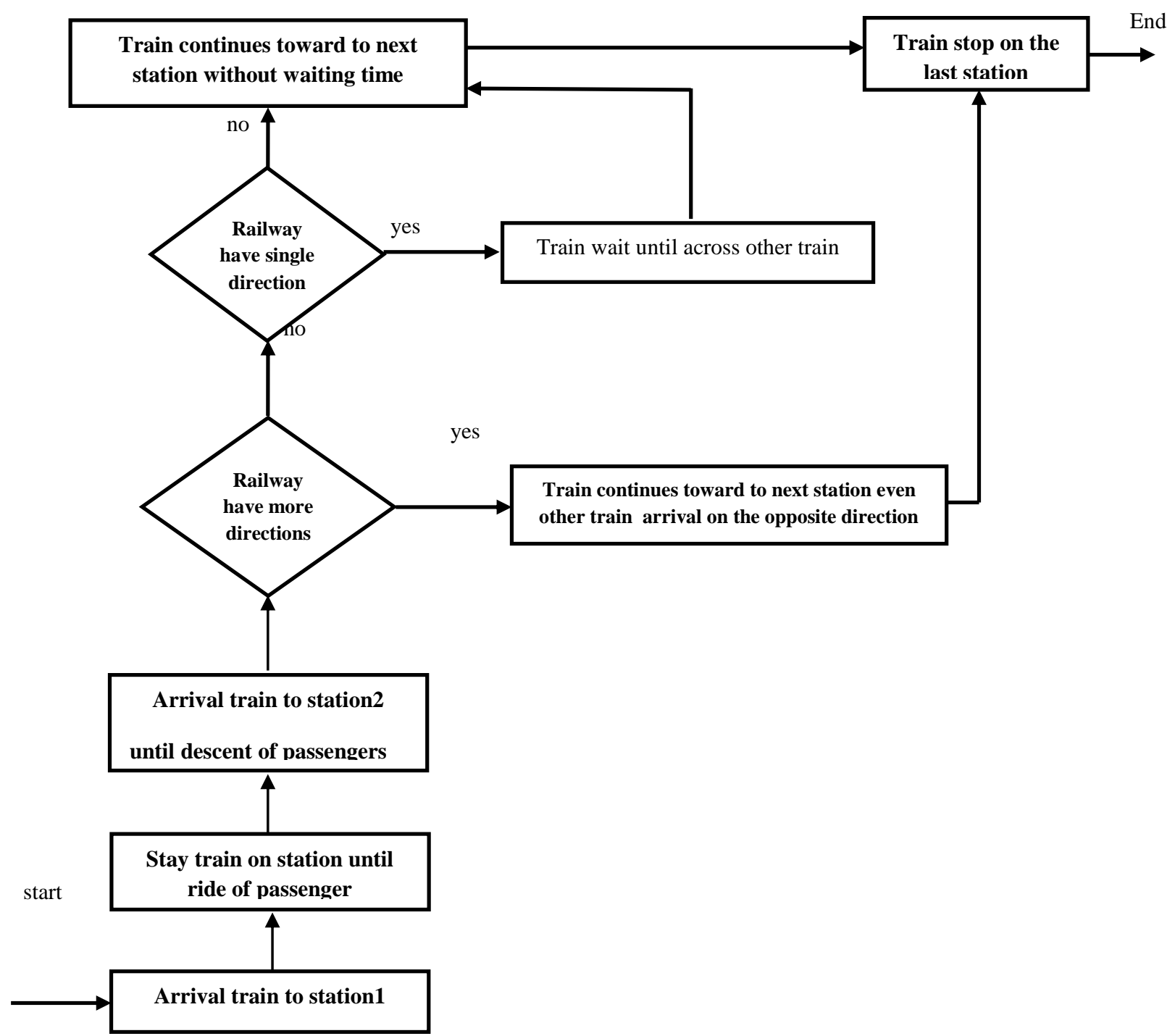

Fig 1: flow chart of proposed train movement model

\subsection{Methodology}

The methodology of simulation models applied to the trains movement on railway by a following steps:

1. Generate Discrete Probability distributed by using function Probability ( variable $_{1}$ ).

2. Using the parameters for a function in the previous step to generate the expected value to calculate the time of inter arrival for trains:

$$
\begin{aligned}
& A_{1}=\text { function }\left(\operatorname{variable}_{1}\right) * \text { variable }_{1} \\
& \operatorname{sum}_{1}(\text { train })=\operatorname{sum}_{1}(\text { train })+A_{1} \\
& \text { inter arrival time }=\operatorname{sum}_{1}(\text { train })
\end{aligned}
$$

3. Generate Discrete Probability distributed by using function Probability ( variable $_{2}$ ).

4. Using the parameters for a function in the previous step to generate the expected value to calculate spend time from station1 toward to station2:

$$
\begin{aligned}
& T_{1}=\text { function }\left(\text { variable }_{2}\right) * \text { variable }_{2} \\
& \operatorname{sum}_{2}(\text { train })=\operatorname{sum}_{2}(\text { train })+T_{1}
\end{aligned}
$$

Time fromstation 1 tow ardto station $2=\operatorname{sum}_{2}($ train $)$

5. Calculate times for trains in single railway (arrival time, waiting time and leave time from last station) but without wait time in double railway.

- arrival time (train) $=$ inter arrival time (previous trains) + arrival time (current trains)

○ Waiting time $(\operatorname{train} 1)=$ leave time $(\operatorname{tain} 2)-$ arrival time (tain2).

- Leave time $(\operatorname{train} 1)=$ arrival time $(\operatorname{train} 1)+$ time from station1 to station2 (train1) + waiting time (train1).

6. Calculate times for trains on double railway (idle time on railway).

$\circ \quad$ Idle time $=$ arrival time - depart time (if arrival > depart of previous trains) 
- Waite time $=$ depart time - arrival time (if depart > arrival of previous trains).

\section{RESULTS AND DISCUSSION}

By means of the created simulation model, with preliminary assigned for the two scenarios, each scenarios have number of trains the incoming flow (access rate), spend time from station 1 to station 2 and leave the trains from the last station are simulated the operations of system "trains movement on railway".

Scenario 1 - simulation of the system "trains movement on railway" as Single-Direction model of railway, having discrete probability incoming flow with an average interaccess time of the transport trains in single railway. In this railway train 1 wait until traffic train 2 is based on priority principle. Figure (2) shows a sample of the program tabular results to simulation model of single railway, and display the results of Rates of Departure trains with waiting time and without as graphical scheme in Figure(3). In the tabular results represent access of train 2 by value of (1) and required wait time and represent not access of train 2 by value (0).

\begin{tabular}{|c|c|c|c|c|c|c|c|}
\hline $\begin{array}{l}\text { Trai } \\
\text { n } \\
\text { No. }\end{array}$ & \begin{tabular}{l}
\multicolumn{1}{c}{ Inter } \\
access \\
Time
\end{tabular} & $\begin{array}{l}\text { Acce } \\
\text { ss } \\
\text { Time }\end{array}$ & $\begin{array}{c}\text { Time from } \\
\text { Station1 To } \\
\text { Station2 }\end{array}$ & $\begin{array}{c}\text { Time } \\
\text { Trai } \\
\text { n }\end{array}$ & $\begin{array}{c}\text { Wait } \\
\text { time } \\
\text { Train }\end{array}$ & $\begin{array}{l}\text { Dept } \\
\text { with } \\
\text { Wait }\end{array}$ & $\begin{array}{c}\text { Dept } \\
\text { without } \\
\text { Wait }\end{array}$ \\
\hline 1 & 0.2 & 0.2 & 0.9 & 0 & 0 & 1.1 & 0 \\
\hline 2 & 0.1 & 0.3 & 1.8 & 1 & 0.8 & 2.9 & 0 \\
\hline 3 & 0.2 & 0.5 & 2.7 & 1 & 2.4 & 5.6 & 0 \\
\hline 4 & 0.4 & 0.9 & 3.6 & 1 & 4.7 & 9.2 & 0 \\
\hline 5 & 0.2 & 1.1 & 4.5 & 1 & 8.1 & 13.7 & 0 \\
\hline 6 & 0.3 & 1.4 & 5.4 & 1 & 12.3 & 19.1 & 0 \\
\hline 7 & 0.4 & 1.8 & 6.3 & 1 & 17.3 & 25.4 & 0 \\
\hline 8 & 0.6 & 2.4 & 7.2 & 1 & 23 & 32.6 & 0 \\
\hline 9 & 0.4 & 2.8 & 8.1 & 1 & 29.8 & 40.7 & 0 \\
\hline 10 & 0.5 & 3.3 & 9 & 1 & 37.4 & 49.7 & 0 \\
\hline 11 & 0.6 & 3.9 & 9.9 & 1 & 45.8 & 59.6 & 0 \\
\hline 12 & 0.8 & 4.7 & 10.8 & 0 & 0 & 15.5 & 15.5 \\
\hline 13 & 0.6 & 5.3 & 11.7 & 1 & 10.2 & 27.2 & 0 \\
\hline 14 & 0.7 & 6 & 12.6 & 0 & 0 & 18.6 & 18.6 \\
\hline
\end{tabular}

Fig 2: tabular results of trains movement on single railway

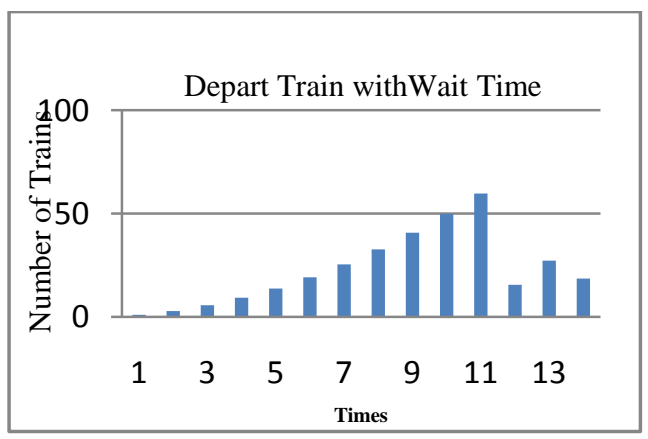

Fig 3: Rates of Depart Trains with Wait Time

Scenario 2 - simulation of the "trains movement on railway" as Double-Direction model of railway, having discrete probability incoming flow with an average interaccess time of the transport trains. Figure (4) shows a sample of the program tabular results to simulation model train moving on double railway which based on parallel principle( train not conflict with other trains), when $x=0.2$ and $y=0.7, z=0.6$ and display the results of departure time of trains from last station as graphical scheme in Figure(5).

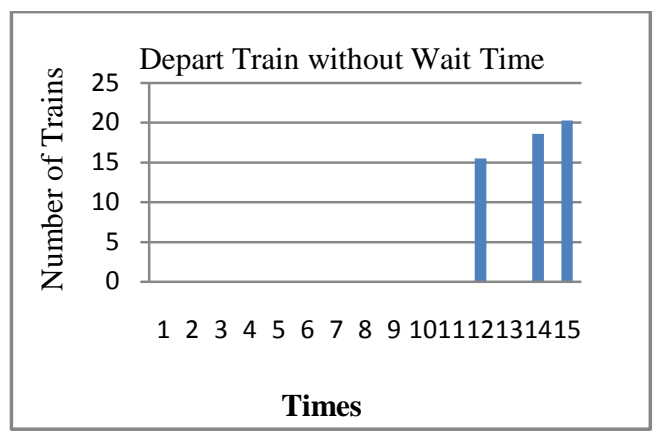

Rates of Depart Trains and without wait time

\begin{tabular}{|c|c|c|c|c|c|c|c|c|}
\hline $\begin{array}{c}\text { Tra } \\
\text { ins } \\
\text { No. }\end{array}$ & $\begin{array}{c}\text { Inte } \\
\text { r } \\
\text { Acce } \\
\text { ss }\end{array}$ & $\begin{array}{c}\text { Acc } \\
\text { ess } \\
\text { time }\end{array}$ & $\begin{array}{c}\text { Wait } \\
\text { ing } \\
\text { time }\end{array}$ & $\begin{array}{c}\text { Idle1 } \\
\text { Rail } \\
\text { way }\end{array}$ & $\begin{array}{c}\text { Idle2 } \\
\text { Rail } \\
\text { way }\end{array}$ & $\begin{array}{c}\text { Trai } \\
\text { n1 } \\
\text { Tim } \\
\text { e }\end{array}$ & $\begin{array}{c}\text { Trai } \\
\text { n2 } \\
\text { Tim } \\
\text { e }\end{array}$ & $\begin{array}{c}\text { Depa } \\
\text { rture } \\
\text { time }\end{array}$ \\
\hline $\mathbf{1}$ & 0.2 & 0.2 & 0 & 0.2 & 0 & 0.7 & 0.6 & 0.9 \\
\hline $\mathbf{2}$ & 0.4 & 0.6 & 0 & 0 & 0.6 & 1.4 & 1.2 & 1.8 \\
\hline $\mathbf{3}$ & 0.6 & 1.2 & 0 & 0.3 & 0 & 2.1 & 1.8 & 3.3 \\
\hline $\mathbf{4}$ & 0.8 & 2 & 0 & 0 & 0.2 & 2.8 & 2.4 & 4.4 \\
\hline $\mathbf{5}$ & 1 & 3 & 0.3 & 0 & 0 & 3.5 & 3 & 6.8 \\
\hline $\mathbf{6}$ & 1.2 & 4.2 & 0.2 & 0 & 0 & 4.2 & 3.6 & 8 \\
\hline $\mathbf{7}$ & 1.4 & 5.6 & 1.2 & 0 & 0 & 4.9 & 4.2 & 11.7 \\
\hline $\mathbf{8}$ & 1.6 & 7.2 & 0.8 & 0 & 0 & 5.6 & 4.8 & 12.8 \\
\hline $\mathbf{9}$ & 1.8 & 9 & 2.7 & 0 & 0 & 6.3 & 5.4 & 18 \\
\hline $\mathbf{1 0}$ & 2 & 11 & 1.8 & 0 & 0 & 7 & 6 & 18.8 \\
\hline $\mathbf{1 1}$ & 2.2 & 13.2 & 4.8 & 0 & 0 & 7.7 & 6.6 & 25.7 \\
\hline $\mathbf{1 2}$ & 2.4 & 15.6 & 3.2 & 0 & 0 & 8.4 & 7.2 & 26 \\
\hline $\mathbf{1 3}$ & 2.6 & 18.2 & 7.5 & 0 & 0 & 9.1 & 7.8 & 34.8 \\
\hline $\mathbf{1 4}$ & 2.8 & 21 & 5 & 0 & 0 & 9.8 & 8.4 & 34.4 \\
\hline $\mathbf{1 5}$ & 3 & 24 & 10.8 & 0 & 0 & 10.5 & 9 & 45.3 \\
\hline $\mathbf{1 6}$ & 3.2 & 27.2 & 7.2 & 0 & 0 & 11.2 & 9.6 & 44 \\
\hline $\mathbf{1 7}$ & 3.4 & 30.6 & 14.7 & 0 & 0 & 11.9 & 10.2 & 57.2 \\
\hline $\mathbf{1 8}$ & 3.6 & 34.2 & 9.8 & 0 & 0 & 12.6 & 10.8 & 54.8 \\
\hline $\mathbf{1 9}$ & 3.8 & 38 & 19.2 & 0 & 0 & 13.3 & 11.4 & 70.5 \\
\hline $\mathbf{2 0}$ & 4 & 42 & 12.8 & 0 & 0 & 14 & 12 & 66.8 \\
\hline $\mathbf{2 1}$ & 4.2 & 46.2 & 24.3 & 0 & 0 & 14.7 & 12.6 & 85.2 \\
\hline $\mathbf{2 2}$ & 4.4 & 50.6 & 16.2 & 0 & 0 & 15.4 & 13.2 & 80 \\
\hline $\mathbf{2 3}$ & 4.6 & 55.2 & 30 & 0 & 0 & 16.1 & 13.8 & 101.3 \\
\hline $\mathbf{2 4}$ & 4.8 & 60 & 20 & 0 & 0 & 16.8 & 14.4 & 94.4 \\
\hline $\mathbf{2 5}$ & 5 & 65 & 36.3 & 0 & 0 & 17.5 & 15 & 118.8 \\
\hline $\mathbf{2 6}$ & 5.2 & 70.2 & 24.2 & 0 & 0 & 18.2 & 15.6 & 110 \\
\hline $\mathbf{2 7}$ & 5.4 & 75.6 & 43.2 & 0 & 0 & 18.9 & 16.2 & 137.7 \\
\hline $\mathbf{2 8}$ & 5.6 & 81.2 & 28.8 & 0 & 0 & 19.6 & 16.8 & 126.8 \\
\hline $\mathbf{2 9}$ & 5.8 & 87 & 50.7 & 0 & 0 & 20.3 & 17.4 & 158 \\
\hline & & & & & & & & \\
\hline
\end{tabular}

Fig 4: tabular results of trains movement on double railway

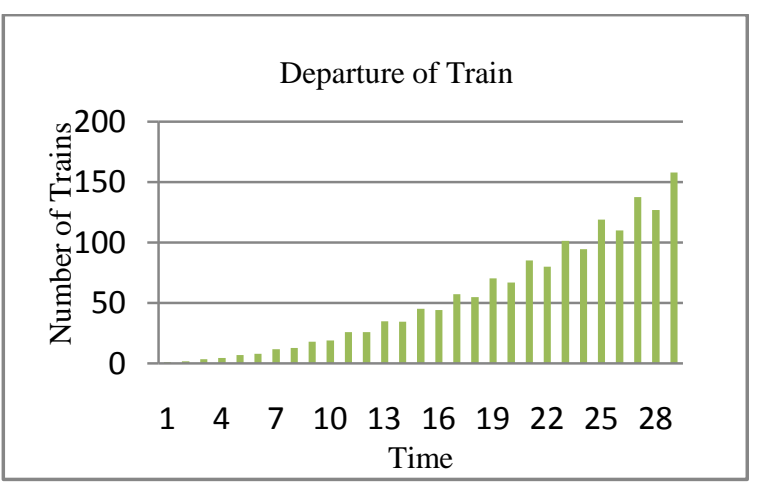

Fig 5 : Rate of departure trains 


\section{CONCLUSIONS}

Finally following conclusions can be drawn:

The method of simulation modeling is a powerful tool for creating models when the processes in the studied systems are difficult or impossible analytically to describe, and the simulation system probability distributed - a powerful tool for describing models and their program implementation. The developed model to simulate moving of the trains through an illustrative railway possesses the following special features:

- The discrete probability using to enhance a new dimension in computer simulations which take to consideration the wait time reduced. Via applying doubledirection model of railway compared with other Single direction model, the minimum waiting time will obtained.

- The priority discipline is measure of urgency or importance, when the train arrival to station before other trains because it's urgent, but waiting time in this state is smaller than without.

\section{REFERENCES}

[1] Robert C. Leachman, "Modeling Train Movements Through Complex Rail Networks", University of California, Berkeley, Vol. 14, No. 1, Pages 48-75, 2004.
[2] Gabriele Malavasi ,"Petri Net Tools for Simulation of Railway Operation", University of Rome La Sapienza DITS - Transport Area, Via Eudossiana, 18 - 00184 Roma Italy,E-Mail:gabriele.malavasi@uniroma1, stefano.ricci@uniroma1,2000.

[3] Ting Li, Freek Hofker, "Passenger Travel Behavior Model in Railway Network Simulation", RSM Erasmus University, P.O. Box 1738, Rotterdam, the Netherlands, 2006.

[4] Y. Bavafa-Toosi, "Modeling, Analysis, Synthesis, and Simulation of Time-Optimal Train Traffic in Large Networks", 2/71, Abuzar 11 St, Ahmadabad Ave, Mashhad 9176885464, Iran, Email: ybavafat@yahoo.com, 2008.

[5] J. Manuel Feliz-Teixeira, "Circles Model for Metro Light Rail Analysis", Email: feliz@fe.up.pt, url: http://geinsrv.fe.up.pt/feliz, 2007.

[6] Ye Jing-Jing and Li Ke-Ping, "Simulation Optimization for Train Movement on a Single-Track Railway", Beijing Jiaotong University, Chin. Phys. B Vol. 22, No. 5 (2013).

[7] Ke Ping Li, Zi You Gao, “An Improved Equation Model for the Train Movement", Beijing Jiaotong University, PRChina, www.elsevier.com/locate/simpat, 2007. 